Original Article

\title{
Knowledge and Attitude on Care of Child during Common Childhood Illnesses among the Koraga Tribes
}

\author{
Shrisha ${ }^{1}$, Binu Margaret $E^{2} \&$ Sheela Shetty ${ }^{2}$ \\ ${ }^{1} \mathrm{M}$ Sc Nursing in Child Health Nursing, M anipal College of Nursing M anipal, M anipal University, ${ }^{2}$ Assistant Professor, \\ Department of Child Health Nursing, Manipal College of Nursing M anipal, M anipal University, Manipal. \\ Correspondence : \\ Binu Margaret E \\ Assistant Professor, Department of Child Health Nursing, M anipal College of Nursing, Manipal University, \\ Manipal, Udupi district - 576 104, Karnataka, India. \\ E-mail : binumarg@gmail.com, binumarg@yahoo.co.in
}

\begin{abstract}
Introduction: Every society follows different practices and beliefs in different traditional aspects related to health care. Majority of Indians have taken pleasure in using traditional beliefs and practices. There are limited numbers of studies related to knowledge and attitude towards care of the child during common childhood illnesses among Indian tribes.
\end{abstract}

Objectives: The objectives of the study were to assess the knowledge and attitude of the Koraga tribes towards care of the child during common childhood illnesses and to find the relationship between knowledge and attitude of tribes during common childhood illnesses.

Materials and Methods : A descriptive survey and face to face interview was undertaken among 200 Koraga tribal care takers using structured questionnaires and an attitude scale. SPSS 16.0 software was used for data analysis. Frequency, Percentage and Pearson correlation co-efficient were used.

Results : The findings of the study showed that, majority 155 (77.5\%) of tribal care takers had good knowledge and majority 158 (79\%) had favorable attitude on care of the child during common childhood illnesses like common cold, diarrhea, fever, tooth ache, ear ache and febrile convulsion. It was also found there was significant positive correlation $(p<0.001)$ between knowledge and attitude.

Conclusion : The study concluded that majority of Koraga tribal care takers have good knowledge and favourable attitude towards care of the child during common childhood illnesses.

Keywords: Knowledge, Attitude, Common Childhood IIInesses, Koraga Tribes, care of child

\section{Introduction}

Healthy children can bring happiness to the society. Each society has different beliefs which includes beliefs in supernatural powers, beliefs in holy rituals, salvation, offerings and sacrifices etc. M ajority of Indians have taken pleasure in following traditional beliefs and practices. Health workers must have concern for the people's cultural values and beliefs. ${ }^{1}$

\begin{tabular}{|c|}
\hline Access this article online \\
\hline Quick Response Code \\
\hline
\end{tabular}

India is famous for its cultural diversity. India has the longest unbroken health tradition which has not only a stream of practitioners but also a textual and theoretical backing in terms of the Ayurvedic and Siddha systems of M edicine. ${ }^{1}$

Tribes constitute $8.2 \%$ of the Indian population. ${ }^{1}$ According to the 2011 census, the tribal population of India was 1, 04,281,034, in Karnataka it was 4,248,987and in Udupi it was $20117{ }^{2}$ Tribal communities are geographically distinct; with each tribe having its own unique customs, traditions, beliefs and practices. Tribal populations are isolated from the general population by their own life styles and practices

A cross sectional study was conducted by Zyoud S, Jabi SW, Sweileh WM et al among 402 parents on beliefs regarding childhood fever in Palestine in 2012. They have conducted face to face interview with the parents with the help of structured questionnaire to gather information regarding their beliefs and practices during childhood fever. The result showed that most of the parents (77.4\%) believed 
that fever in a child is the result of symptom of some of the illnesses and $19.4 \%$ of them believed that fever is natural result of child's growth. And also parents believed that fever is dangerous and cause various harmful effects to the child if it is not treated properly. Most of them(38.1\%) believed that it may cause brain damage, $15.7 \%$ of believed that it may result in dehydration and $14.2 \%$ believed that fever may results in damage to the vital organs like kidney, liver etc. $^{3}$

A study was conducted by Sreeramareddy CT, Shankar RP, Ravi $P$ et al. in 2005, on care seeking behaviour for childhood illness among 292 mothers of children suffering from illness during the preceding 15 days in western Nepal. A cross sectional survey was conducted and mothers were interviewed through structured questionnaire by trained health workers. The results showed that majority of mothers were aware of fever (51\%), child becoming sicker (45.2\%) and drinking poorly (42.5\%) as the danger signs of childhood illness. ${ }^{4}$

In today's age of evidence- based medicine and continuing use of folk remedies for the treatment of medical conditions warrants evaluation. While going through the literatures, there are limited numbers of studies related to knowledge, attitude, and practices during common childhood illnesses among Indian tribes. Therefore an initial step is necessary to highlight the knowledge and attitude among the tribes during common childhood illnesses. This initiation gives indepth information for the necessity to provide awareness programme if their knowledge and attitude are found unsatisfied.

The purpose of the study is to assess the knowledge and attitude of the Koraga tribes on care of the child during common childhood illnesses. This will help to get a baseline data and in depth information, so as to provide awareness on care of the child during common childhood illnesses.

\section{Materials and method}

A descriptive survey was conducted among 200 Koraga tribal care takers residing in selected tribal areas of Kundapur Taluk, Udupi District, Karnataka. Cluster random sampling technique was used to select the research settings and final sample were selected through purposive sampling technique. Face to face interview with the help of structured questionnaire was used to collect data.

Data were collected after obtaining permission from concerned authorities like Department of Scheduled Tribes, Udupi District and informed consent from the participants. Ethical clearance was taken from the institutional ethical committee of Kasturba Hospital. Pretested, valid and reliable tools developed by the investigator were used. The tools include: Background data for collecting background information of the Koraga tribes. It consisted of five items. The items included were age, gender, education level, type of family and previous information on care of the child during common illnesses and the source of information.

The knowledge questionnaire was developed to assess the knowledge level of Koraga tribes on care of the child during common childhood illnesses. It consisted a total of 40 items and divided into section $\mathrm{A}$, which had 35 multiple choice questions and section $B$, which had five true or false types of questions. The areas included in the tool were knowledge on care of the child during common cold, fever, diarrhea, tooth ache, ear ache and febrile convulsion. Each item was carrying a score of one for correct answer and a score of zero for wrong answer. The knowledge score was arbitrarily classified as: Poor knowledge $=0$ to 13 , Average knowledge $=14$ to 26 , and Good knowledge $=27$ to 40. The reliability co- efficient of knowledge questionnaire was found to be $r=0.82$ by spilt half method.

A five point likert type of Attitude scale on care of the child during common childhood illnesses which consisted of 14 items was developed to assess the attitude of the Koraga tribes towards care of the child during common childhood illnesses. The areas included were, attitude towards care of the child during common cold, fever, diarrhea, tooth ache, ear ache and febrile convulsion. The scoring for each positive item was given as: $1=$ strongly disagree, $2=$ disagree, $3=$ not sure, $4=$ agree and $5=$ strongly agree . Reverse scoring was given for the negative items. The 
attitude score was arbitrarily classified as: 14 to $31=$ unfavorable, 32 to $50=$ moderately favorable and 51 to $70=$ favorable. The reliability co- efficient of attitude scale was found to be $r=1$ by cronbach's alpha method.

The data was collected by the investigator using face to face interview technique, after giving the subject information sheet about the study and obtaining informed consent from each participant. The data collected were analysed using descriptive and inferential statistics.

\section{Results}

The findings of the study were discussed under the following headings:

Description of Sample Characteristics:

The analysis of the baseline characteristics presented in table 1 revealed that majority of the care takers 139 (69.5\%) belonged to the age group of 36-52 years, majority 168 (84\%) were female care takers, majority 116 (58.0\%) had educational qualification of primary school, majority of them 148 (74\%) were living in nuclear families. M ajority 197 (98.5\%) had previous information related to care of the children during common childhood illnesses and source of information was from health personnel for majority 155 (77.5\%) of them.

Description of level of Knowledge regarding common childhood illness among the Koraga tribes:

The study findings revealed that majority 155 (77.5\%) of the sample had good knowledge, most of them 45 (22.5\%) had average knowledge and none of them had poor knowledge.

The mean and standard deviation of the knowledge score regarding the common childhood illness is $29.23 \pm 4.06$. The area wise level of knowledge regarding the common childhood illness is depicted in table 2.

Description of attitude regarding common childhood illness among the Koraga tribes:

M ajority 158 (79\%) of the sample had favourable attitude, $42(21 \%)$ of them had moderately favourable attitude and none of them had unfavourable attitude on care of the child during common childhood illnesses. The mean attitude score regarding the common childhood illness is $52.75 \pm 3.82$

Relationship between knowledge and attitude score regarding common childhood illness among the Koraga tribes:

The relationship between knowledge and attitude on common childhood illness was computed using Pearson's correlation coefficient It revealed that there was a significant positive correlation $(r=.334, p \varangle 0.001)$ between knowledge and attitude, which indicates that as knowledge level increases attitude level also increases.

\section{Discussion}

The findings of the present study showed that, majority $155(77.5 \%)$ of tribal care taker had good knowledge with a mean score of $29.235 \pm 4.066$ and 158 (79\%) had favorable attitude with a mean score of $52.755 \pm 3.825$ on care of the child during common childhood illnesses. These findings are supported by another study conducted by Khalili M, M irshahi M et al. in 2012 in Zahedan, Iran on maternal knowledge regarding childhood diarrhea and diet, showed that knowledge of the majority of mothers (64.3\%) regarding diarrhea and diet was moderate and only 3.7\% had good knowledge. The majority of mothers (56\%) had a moderate practicing knowledge of diarrhea and diet and only $2.3 \%$ had a good practice. ${ }^{5}$ This study partially supports the findings of present study. ${ }^{5}$

The findings of the present study is contradicted by a study conducted by Srikanth SI, Isaac R, Rebekah G, et al on Knowledge, attitudes and practices with respect to risk factors for otitis media in a rural South Indian community. The result showed that around $50 \%$ of care givers are lacking in regard to risk factors for the occurrence of earache and ear infections. Caregivers from nuclear families were slightly less knowledgeable regarding lack of immunization and household smoke as risk factors for the disease. $^{6}$ 


\section{Conclusion}

Koraga tribal care takers knowledge and attitude level on caring the child during common childhood illnesses is comparatively good. It has given a base to look into their different practices during various common childhood illnesses.

Table 1: Description of sample characteristics in frequency and percentage $\mathrm{n}=200$

\begin{tabular}{|c|c|c|c|c|}
\hline S.I & Sample char & acteristics & Frequency $(\mathrm{f})$ & Percentage (\%) \\
\hline 1 & \begin{tabular}{|l|l} 
Age \\
\end{tabular} & $18-35$ & 51 & 25.5 \\
\hline & & $36-52$ & 139 & 69.5 \\
\hline & & $53-70$ & 10 & 05 \\
\hline 2 & Gender & Female & 168 & 84.0 \\
\hline & & Male & 32 & 16.0 \\
\hline 3 & Education & & & \\
\hline & No formal ec & ducation & 54 & 27.0 \\
\hline & & Primary & 116 & 58.0 \\
\hline & & High school & 26 & 13.0 \\
\hline & & PUC & 1 & .5 \\
\hline & & Graduation & 3 & 1.5 \\
\hline 4 & Type of fami & & & \\
\hline & & Nuclear & 148 & 74.0 \\
\hline & & Joint & 52 & 26.0 \\
\hline 5 & Previous & No & 3 & 1.5 \\
\hline & information & Yes & 197 & 98.5 \\
\hline 6 & Source of inf & formation & & \\
\hline & & Family member & 42 & 21.0 \\
\hline & & Healthcare & & \\
\hline & & professionals & 155 & 77.5 \\
\hline & & Mass medias & 3 & 1.5 \\
\hline
\end{tabular}

\section{References}

1. Balasubramanian A V. Indian health traditions. The Hindu. October 08; 2000. http://tribal.nic.in/Content/STATISTICSDivision.aspx.

2. Zyoud S, Jabi S W, Sweileh W M, Nabulsi M M, Tubaili M F, Awang R, Sawalha AFI. Beliefs and practices regarding childhood fever among parents. BM CPediatrics 2013; 13(66).

3. Sreeramareddy CT, Shankar RP, Ravi P, Sreekumaran BV, Subba SH, Joshi HS, Ramachandran U. Care seeking behavior for childhood illness. BM CInternational Health and Human Rights. 2006; 6(7).

4. Khalili M, Mirshahi M, Zarghami A, Rajabnia, Farahmand F. M aternal knowledge regarding childhood diarrhea and diet. BM C Public Health 2011; 12:389.

5. Srikanth $\mathrm{SI}$, Isaac R, Rebekah G, Rupa V. Knowledge, attitudes and practices with respect to risk factors for otitis media in a rural South Indian community. Int J Pediatric Otorhinolaryngology. 2009; 73(10):1394-8.

\section{Acknowledgement}

Our gratitude to Dr. Anice George, Dean, M anipal College of Nursing Manipal, Dr. Baby S Nayak, Head of the department, Department of Child Health Nursing, M anipal College of Nursing Manipal for their timely help and support. We extend our gratitude to all the validators of tools and the friends who provided the technical support for the study.

Table 2: M ean and standard deviation of area wise knowledge level on care of the child during common childhood illnesses.

\begin{tabular}{|l|c|c|c|}
\hline Areas of knowledge & $\begin{array}{c}\text { Maximum } \\
\text { possible } \\
\text { score }\end{array}$ & Mean & $\begin{array}{c}\text { Standard } \\
\text { deviation }\end{array}$ \\
\hline $\begin{array}{l}\text { Common childhood } \\
\text { illness }\end{array}$ & 2 & 1.7100 & 0.45490 \\
\hline Common cold & 8 & 6.8250 & 0.94809 \\
\hline Diarrhoea & 12 & 8.8050 & 1.22658 \\
\hline Fever & 5 & 3.9200 & 0.81666 \\
\hline Tooth ache & 5 & 3.9000 & 0.92969 \\
\hline Ear ache & 2 & 1.4400 & 0.49763 \\
\hline Febrile convulsion & 6 & 2.4950 & 1.06094 \\
\hline
\end{tabular}

